\title{
Sistema Penitenciário do Estado de São Paulo.
}

\author{
Manoel Pedro Pimentel \\ Professor Titular de Direito Penal na Faculdade \\ de Direito da Universidade de São Paulo. Secretário \\ da Justiça do Estado de São Paulo.
}

A minha presença nesta solenidade, atendendo ao honroso convite que me foi feito, tem o sentido do cumprimento de uma obrigação, ao mesmo tempo afetiva e funcional, pois aqui compareço na qualidade de amigo desta Casa e de Secretário da Justiça do Estado de São Paulo.

Minha intenção, aqui comparecendo, é apenas a de dar um testemunho de verdade e de sinceridade, procurando informar aos estudiosos da Ciência Penitenciária e de Direito Penal o que se passa no sistema penitenciário do Estado de São Paulo.

Para o bom esclarecimento dos pontos que serão tocados nesta palestra, devo colocar-me diante do problema, definindo o meu pensamento a respeito da pena de prisão e da sua aplicação.

A origem da pena, em si, é muito discutida e penso que não há possibilidade de uma afirmação inconteste a respeito. Será sempre questionada essa origem, que se perde nos primeiros albores da humanidade. Todavia, alguns dados cientificamente apurados nos permitem formular uma teoria, tão boa quanto as demais.

*. Conferência pronunclada na Faculdade de Direito da Universidado Federal do Paraná, Curitiba, em 9-6-75. 
Estamos convencidos de que a pena teve, na origem, o caráter sacral. A idéia de punição, acreditamos, não está ligada ontologicamente à idéia de vingança, quer pública, quer privada. A pena - reação jurídica contra o crime - é uma categoria racional, enquanto que a vingança - reação emocional contra um dano - é uma categoria irracional. Ambas, pena e vingança, certamiente coexistiram em certo período histórico, porém não eram a mesma coisa. Após essa experiência a pena continuou sendo a reação jurídica contra o crime e a vingança prosseguiu na sua caracterização de reação emocional contra o dano.

O caráter sacral da pena cifra-se, sobretudo, na pesquisa das primeiras formàs de punição conhecidas, e que eram, sem dúvida, representadas pelas reações contra o desrespeito aos tabus.

O homem primitivo não se regia pelo princípio da razão, mas se impulsionava por reações ditadas pelos sentimentos. E natural que assim fosse, porque sua visão cósmica era muito limitada, servida por um conhecimento exígüo de realidade que o cercava e sem possibilidade de compreender o mundo da natureza e os seus fenômenos.

Para o homem primitivo, o que parecia ser, era. Não podendo explicar fenômenos objetivos, atribuiria os efeitos visíveis a causas misteriosas, sobrenaturais. A chuva, o vento, o trovão, os terremotos, eram sempre atribuídos a manifestações de uma vontade superior. Cedo acreditou que poderia, de certa forma, obter as boas graças dos entes sobrenaturais mudando a vontade, que se fazia imperiosa, através de oferendas e sacrifícios, com os quais se deleitavam e se tornavam propícias as deidades.

Daí os rituais de cunho religioso encontrados em todos os agrupamentos humanos primitivos, cujas expressões mais antigas, em termos culturais, são as instituições do totem e do tabu. O totem significando o aspecto positivo do culto, com 
a entronização de um símbolo, geralmente um animal, que traria a proteção e a felicidade a um homem, a um grupo, ou a um clã.

Interessa-nos, no entanto, de modo particular, a instituição tabu. A palavra tabu, de origem polinésia, não tem significado preciso. Como o vocábulo sacer, do latim, tanto pode indicar o sagrado como o terrível. Parece-nos que o tabu tinha uma função normativa na horda, visando declarar proibidos determinados comportamentos, tidos como prejudiciais para os integrantes do grupo.

Vamos dar um exemplo bem simples: se alguém do grupo, em um dia de chuva, fosse atingido por um raio e morresse no momento em que tentava apanhar um fruto, tornava-se proibido apanhar frutos em dias de chuva. O simples acontecimento fatal, objetivamente constatado, fazia acreditar que um deus desconhecido não aprovava a conduta de apanhar frutos nos dias de chuva. E, irritado, mandava a morte ao transgressor.

Acreditavam, também, que o castigo ministrado ao ofensor tinha força para liberar os demais de qualquer punição. Por isso era preciso castigar sempre o infrator, para evitar que o deus desconhecido, enfurecido, viesse a castigar todo o grupo. E o grupo passou a assumir o encargo de punir, mostrando os autores que mais se aprofundaram no exame do assunto, que a isso se deve o fato de serem de caráter coletivo os primeiros castigos. A lapidação é uma das formas mais antigas de execução que se conhece. Era preciso que todos do grupo participassem da punição do infrator, a fim de que todos se lilivrassem da eventual ira da entidade ofendida.

O que se percebe claramente, através desta forma de examinar o problema, é que a pena não era propriamente uma vingança, mas a expressão de um temor de castigo. $\mathrm{O}$ ofensor era punido pelo grupo temeroso de uma reação sobrenatural, 
para evitar um castigo indiscriminado a todo o grupo, e não porque se exercesse sobre o infrator um ato de vigança.

Mas, é da natureza do homem, em uma outra ordem de considerações, desejar a reparação do mal com a prática da vingança. As leis de alguns povos, já na fase histórica mais conhecida, consagraram a vinganca proporcional. conhecida como o talião. $\mathrm{E}$, até agora. não desanareceu inteiramente $\mathrm{o}$. sentimento de que a pena deve atribular o criminoso, fazê-lo sofrer, não sendo raros os que sustentam que a palavra pena deriva da expressão grega ponos, que significa castigo, dor, suplício.

Dessa mistura de conceitos é que deriva uma das mais importantes distorções encontradas no campo da ciência penal. Afastada a idéia do tabu pelos postulados da experiência científica, que autorizam uma nova visão cósmica, e não admitida eticamente a idéia da vingança, persistiu, todavia, a crença de que a pena deve ter uma conotação de castigo e, ao mesmo tempo, de reparação emocional ao ofendido.

Este é o erro de perspectiva que mais contribuiu para o atraso da penologia. Apesar da influência do jusnaturalismo, afastando o teocentrismo da idéia do direito, a Escola Clássica persistiu na afirmacão do caráter retribuitivo da pena. A reação positivista não bastou para eliminar totalmente o ranço aflitivo da sanção penal. Somente agora, depois da colocação feita pelos pregadores da Escola Técnico-Jurídica, é que se chegou a um novo conceito da pena, a partir do entendimento de que a pena é uma reação jurídica contra o crime. O Neodefensismo social contemporâneo permitiu a compreensão do caráter utilitário da sanção penal, e recomenda o seu emprego como um meio de defesa atuante não apenas em favor da sociedade, mas igualmente em favor do réu.

Nesse contexto é que deve ser analisada a pena de prisão. Nascida no século $V$, teve inicialmente aplicação apenas nos mosteiros. A Igreja não podia impor penas seculares, especial- 
mente a pena de morte. Daí encarecer o valor da segregação, que favorecia a penitência. $O$ encarceramento na cela, chamado in pace, deu origem à chamada prisão celular, nome que até bem pouco tempo era usado na legislação penal.

Transplantado o sistema para o âmbito secular, a prisão se converteu na forma principal de punição a partir da segunda metade do século passado. Todavia, é unânime a afirmação dos estudiosos, fracassou como forma de punir em si mesma. Proclama-se hoje, em todos os congressos nacionais e internacionais, que a prisão não é, finalisticamente considerada em si mesma, uma forma adequada para que sejam atingidos os objetivos da pena.

No entanto, esta é a grande verdade, ainda estamos usando as prisões como meio para punir, sem outro fim que não a punição em si mesma. $O$ prestígio da pena de prisão está declinando, mas ainda não se encontrou um substitutivo ideal, capaz de eliminar os inconvenientes que ela acarreta. Continuamos a lançar mão da prisão como se fosse o melhor remédio, quando está provado que é apenas uma panacéia.

A conseqüiência, porém, é que este enfoque exige um esforço para a construção de prisões, insuportável do ponto de vista econômico, e que se esvai na inutilidade da reclusão que deixa de ser acompanhada do necessário tratamento penal. Podemos afirmar, agora, que a prisão somente se justifica como uma oportunidade para o recolhimento do sentenciado, propiciando-lhe o adequado tratamento, capaz de recuperá-lo para a vida em sociedade.

O espetáculo que hoje se oferece ao observador mais desprevenido é o das prisões superlotadas, sem um mínimo de condições para cumprirem o seu objetivo de ensejar o necessário tratamento penal.

E o que acontece no Estado de São Paulo. Ao lado de um sistema penitenciário bem organizado, que possibilita o 
satisfatório tratamentio penal para cerca de 2.000 sentenciados, temos uma lamentável rede de depósitos de presos, onde se amontoam aproximadamente 10.000 detentos, sem qualquer possibilidade de receber um mínimo de atenção e de tratamento.

A saída para o impasse não pode ser meramente o expediente de construção de presídios, com a finalidade de acomodar melhor e de propiciar o tratamento penal a esse grande número de sentenciados amontoados em exígüo númiero de vagas. Uma demonstração feita com os dados concretos basta para convencer de que não está aí a solução. Vamos falar do Estado de São Paulo, que é o que melhor conhecemos.

Existem, hoje, nas Cadeias Públicas administradas pela Secretaria da Segurança Pública, 6.517 sentenciados definitivamente condenados, que deveriam estar recolhidos em Presídios da Secretaria da Justiça. A Casa de Detenção de São Paulo, construída para oferecer 2.200 vagas, conta hoje com uma população carcerária da ordem de 5.705 presos. Há, porranto, um excesso de 10.000 homens, em números redondos, somente na área da Secretaria da Justiça, sem contar os excedentes na área da Secretaria da Segurança Pública.

Para absorver o excesso na área da Secretaria da Justiça, e tendo em vista que a lotação ideal de um presídio é da ordem de 500 presos, seria necessário construir 20 penitenciárias iguais a que se está construindo em Araraquara. Todavia, o custo de uma penitenciária de segurança máxima, como a indicada, é da ordem de cem milhões de cruzeiros, segundo estimativa atual. Assim sendo, o custo total dessas 20 penitenciárias seria de aproximadamente 2 bilhões de cruzeiros.

Mas, não é tudo. Existem no Estado de São Paulo mais de 75.000 mandados de prisão por cumprir. Presume-se que esse número de mandados não corresponda exatamente ao número de pessoas que devem ser presas. Muitos mandados se referem à mesma pessoa. Outros decorrem de prisões pre- 
ventivas já caducas, enquanto que outros mais se relacionam com penas já prescritas.

Dando um balanço muito otimista, podemos chegar a um número estimado em 20.000 mandados ativos, que devem ser cumpridos e, assim, à necessidade de construir outras 40 penitenciárias na rede de presidíos da Secretaria da Justiça, o que traria nova despesa, desta vez da ordem de 4 bilhões de cruzeiros que somados aos 2 bilhões já mencionados, importariam na despesa total de 6 bilhões de cruzeiros, cifra que comprovadamente é impossível de ser atendida pelo mais generoso dos orçamentos no prazo de 50 anos.

Finalmente, ainda que pudessemos admitir tal extravagância, devemos recordar que os mandados de prisão crescem à razão de 1.000 por mês, o que demandaria o esforço paralelo da construção, além das já mencionadas, de duas penitenciárias por mês.

Penso que não errarei se afirmar que é impossível resolver o grave problema através do expediente de construir presídios. A solução deve ser buscada alhures, criando-se novas formas de punir e reservando-se os presídios de segurança máxima para os casos de sentenciados perigosos, que devam efetivamente receber o tratamento penal no regime carcerário fechado.

Isto acontece no maior Estado da Federação, e que até hoje construiu o melhor sistema penitenciário do país. Contamos, na rede de presídios da Secretaria da Justiça, com o mais completo elenco de prisões, cumprindo rigorosamente o que foi determinado pelo Código penal de 1940. E, acreditamos, somente o. Estado de São Paulo construiu uma Casa de Custódia e Tratamento e um Instituto de Reeducação para os perigosos imputáveis, além dos Institutos Penais Agrícolas de Bauru e de São José do Rio Preto, considerados modelares por quantos os visitam. 
Acrescentando-se a estas observações a circunstância de que $60 \%$ das Cadeias Públicas, da rede da Secretaria da Segurança Pública, estão interditadas, podemos formar uma idéia do que é a realidade, hoje, no Estado de São Paulo. De um lado, um sistema penitenciário bom, atendendo a uma população de cerca de 2.000 sentenciados. De outro, uma carência enorme de vagas, para recolher os condenados que se encontram amontoados em precárias Cadeias, além da necessidade de construção de novos presídios para recolher os sentenciados, cujos mandados de prisão não podem ser cumpridos, exatamente porque não há possibilidade de recolhimento nos estabelecimentos penais.

Pergunta-se, então, qual a solução?

Penso que não é possível dar uma resposta simples a esta pergunta aparentemente tão singela. Em termos de construção, a nossa previsão, para um período relativamente curto, é esta: recuperação de 217 celas no segundo raio do terceiro pavilhão da Penitenciária Estadual da Capital; construção de mais dois pavilhões na Casa de Detenção, para recolher 800 sentenciados; término da construção das Penitenciárias de Araraquara ( 500 sentenciados); Itirapina (250 sentenciados); Sorocaba (250 sentenciados), perfazendo o total de 2.017 vagas, o que daria para absorver uma parte do excesso de presos recolhidos à Casa de Detenção.

Em termos de soluções criativas, verificamos que há necessidade de incentivar os meios que impeçam o fluxo de ingresso de novos condenados na Casa de Detenção. Entre esses meios pensamos na Prisão Albergue, como a solução mais adequada. Entretanto, não é fácil a execução dessa idéia, que exige a construção das Casas do Albergado, não previstas anteriormente nos planos da Secretaria da Justiça.

O recente Provimento XCII, do Egrégio Conselho Superior da Magistratura de São Paulo, ensejou um exame do assunto, mostrando que existem nos presídios da Secretaria da Justiça cerca de 2.000 sentenciados com direito ao benefício. 
Ora, não é possível a imediata transferência desses sentenciados, porque não há estabelecimentos próprios para recolhê-los, sem contar que é desconhecido o número de novos condenados que teriam o mesmo direito.

Além deste problema, há que se considerar a necessidade de preparo de toda a infra-estrutura do novo sistema, com a formação de pessoal próprio e do aparelhamento dos estabelecimentos para receber os albergados. Não podemos afirmar, portanto, que a Prisão Albergue seja uma solução a curto prazo.

Acreditamos que um reforço ponderável para a solução do grave problema seria a alteração de certos dispositivos do Código penal, alguns dos quais já foram modificados pela Lei n. ${ }^{0}$ 6.016, de 31 de dezembro de 1973. Seria preciso dar ao sursis uma extensão maior; conferir vigência imediata ao instituto da prescrição da reincidência; permitir maior franquia ao perdão judicial; erigir as penas acessórias à categoria de penas principais; reservar os presídios de segurança máxima para os sentenciados realmente perigosos, permitindo outros tipos de tratamento penal aos de escassa ou de nenhuma periculosidade.

Estas sugestões serão feitas brevemente ao Excelentíssimo Sr. Ministro da Justiça por um Grupo de Trabalho constituído pelo Governo do Estado para tal fim. Esperamos que haja receptividade para as novas idéias, o que traria certamente um alívio para a situação que é, realmente, dramática.

Para completar o quadro das soluções que entendemos viáveis, estamos trabalhando no sentido de efetuar um levantamento de dados, visando ao conhecimento mais aprofundado dos problemas emergentes. Constituimos dois Grupos de Trabalho: o primeiro examinará o problema do ensino e do trabalho penitenciário, com o objetivo de dinamizar a produção industrial e agro-pecuária dos presídios, permitindo um 
aproveitamento da mão de obra dos sentenciados. As vantagens, quer como terapia penal, quer como fonte de maior renda para os presos e suas famílias, são notórias. Além disso, o Estado poderá recuperar, como retorno, uma parte dos investimentos que faz no sistema penitenciário, ainda que com a única intenção de reverter tais benefícios em favor do próprio sistema penitenciário. O segundo Grupo de Trabalho cuidará do planejamento e da orientação de pesquisas imprescindíveis para uma tomada de consciência a respeito dos problemas envolvidos na ampliação do sistema penitenciário, inclusive com vistas à implantação da Prisão Albergue.

Nem todos sabem que um preso custa para o Estado, somente quanto à alimentação, cerca de Cr. $\$ 700,00$ por mês, sendo certo que o seu custo global, levando-se em conta todas as despesas, inclusive as de capital, é de aproximadamente Cr.\$4.000 mensais. Esta é uma situação sumamente onerosa e injusta, que deve cessar. Muitos homens de bem, com família numerosa, vivendo honestamente, não dispõem de recursos tão significativos para enfrentar as dificuldades da vida qüotidiana. Esta situação também precisa ser encarada com senso de realidade, para que o delinqüente não se converta em um privilegiado beneficiário de um tipo de vida, às custas do Estado.

E preciso, portanto, uma mudança de atitude frente aos problemas do crime e da pena. E preciso que a sociedade mude sua atitude frente ao criminoso, procurando compreendêlo, e considerando-o como sujeito de uma recuperação e não objeto de castigo. Mas é preciso que o sentenciado também mude de atitude frente à sociedade, encarando-a com respeito e procurando tornar-se responsável pela sua própria recuperação, assumindo-se como pessoa e dirigindo satisfatoriamente o seu destino, com vistas ao retorno à vida social, como elemento útil na comunidade.

Tudo isto depende muito de todos nós. Todos somos responsáveis. O crime é, antes de mais nada, um fenômeno 
social. E todos os que vivem em sociedade devem ter interesse na extinção desse fenômeno, ou pelo menos na redução da sua freqüência. É preciso prestar atenção no que acontece à nossa volta, com o nosso vizinho, com o nosso empregado. E preciso olhar com carinho pelo menor abandonado, amparálo e cuidar dele, sem esperar que isso seja feito exclusivamente pelo Estado e pelas autoridades. É preciso olhar com zelo pelo homem marginalizado, pelo "volante", pelo "boia-fria", pelo migrante. Todos somos responsáveis, porque todos somos parte da mesma sociedade humana.

Conta uma lenda antiga que o castigo imposto pelo rei a certos prisioneiros consistia na morte pela fome, embora os condenados estivessem sentados à frente de pratos da melhor comida, renovados todos os dias. Tinham eles os braços presos por sistemas que impediam os gestos levar a comida à própria boca. E assim estavam definhando, até que um dia, um deles, prestanto atenção no sofrimento do vizinho, esqueceu-se de si mesmo, da sua fome, e procurou socorrê-lo. Verificou, entāo, com grande surpresa, que podia alcançar com seus movimentos a boca do vizinho e, assim, alimentou-o. Os demais companheiros vendo aquele gesto, fizeram a mesma coisa, e passaram a alimentar o prisioneiro que estava ao seu lado. E, todos fizeram o mesmo, de sorte que puderam alimentar-se. $\mathrm{E}$ o. rei, tomando conhecimento desse gesto de solidariedade, mandou que todos fossem libertados.

Penso que é isto que devemos fazer. Deixei minha vida calma, minha aposentadoria, meus estudos, meus alunos e até mesmo, em parte, minha família. Penso que procurei alimentar o meu vizinho. Quem sabe se parte da solução não. estaria no esforço que todos fizessem para compreender e para ajudar o próximo? 